What is the "College-Educated Voter"?

Analysis and Discussion of Education Levels and 2020 Voter Data.

Irene Harwarth, $\mathrm{PhD}$

Cynthia Miller, $\mathrm{PhD}$

ireneharwarth@yahoo.com

drcynthia.miller@gmail.com 
The 2016, 2018, and 2020 elections brought unprecedented attention to political polling and especially to analysis of voter preferences by education level. In addition to affecting collection of voter data, how a survey defines and categorizes college attendance and completion and whether participants are presented with levels to define their educational attainment or whether they self-identify, can also affect analysis of voter data collected in surveys of voter preference. This paper examines the current polls leading up to the 2020 election and the impact that defining education may have on predicting outcomes.

Keywords: Election Polling, Polling variables, Presidential Election, Voting, Education, Collegeeducated. 
The 2016, 2018, and 2020 elections brought unprecedented attention to political polling and especially to analysis of voter preferences by education level. Americans widely viewed the presidential polling in 2016 as problematic as most polls predicted a Democratic win contradictory to the eventual election results (Cohn, 2017a,b; Yglesias, 2019). The quality of political polling received more attention in 2018 and was the focus of several articles not only in academic journals but also in the mainstream media from 2017 through 2020 (CNBC, 2020; Skelley \& Rakich, 2020).

While there is evidence that presidential polling at the national level in the 2016 election was close to the results of the popular vote, the swing states (those that swung the Electoral College), were not accurately predicted in their polling. Not enough attention was paid to the fact that there was evidence that Republican victories were possible within the margin of error. The margin of error describes how close a survey response can get to how the true population is voting (Mercer, 2016). According to Dimock (2020), the American public expects pre-election polls to have answers that they may not be able to realistically provide with an emphasis on who is ahead and by how much. With only six percent on average response rates for polls recently, there is increasing difficulty in getting a representative sample of respondents. The focus should be on the potential sources of polling error, including the impact that education level may have on polling error (Leonhardt, 2020).

As one of the more prominent applications of survey research, election polling provides insight into correlations between voter opinion, demographics, and preference (Pew Research Center, 2020). Yglesias describes how the polls in 2016 showed Trump was unpopular, yet he became president anyway, driven by swing states and reflected in a few properly weighted polls that mirrored the results of the 2016 election (Yglesias, 2019). But many polls were not 
weighted to consider the education level of the voter (Cohn, 2017a). As a result, more attention was paid in 2020 to what has been called the "College-Educated Voter" as voter preference data is analyzed regarding the 2020 election. In examining the 2020 election results, the Pew Research Center had variables weighted by Education and Gender, along with Education and Age, from the American Trends Panel Surveys completed in 2016, 2018 and 2020 (Igielnik, Keeter, \& Hartig, 2021).

An evaluation of the 2016 election commissioned by the American Association for Public Opinion Research examined national and state-level polls for the reasons why polls underestimated support for the Republican candidate Trump. The evaluation found several possible factors, including a change in voter preferences in the final week or so of the campaign, adjustments for over-representation of college graduates that many polls did not implement, and the late self-identification of Trump voters. National polls tended to be generally accurate by historical standards, but polls in key states did not all adjust regarding the educational backgrounds of poll participants, which led to an under-estimation of support for Trump (American Association for Public Opinion Research, 2017). One of the key elements that has been identified as a measure in polling has been the correlation of level of education and vote. Having a consistent measure of level of education across polling sources has proven problematic.

\section{The importance of the College-Educated Voter}

What is meant by the term "College-Educated Voter"? Close examination of political polling reveals some discrepancies in the underlying assumptions tied to the term "CollegeEducated." Review of survey development, data collection, analysis, and reporting can provide insight into the problems associated with the use of this term as an overarching description of education levels of voters in discussing voting preferences. 
The term "College-Educated" voter can sometimes include participants who have had some college, are college graduates, are four-year college graduates or have degrees beyond four years of college, and the terms "No College" or "Non-College Graduate", which sometimes can mean high school graduates, but can sometimes mean high school graduates with some college (and therefore can sometimes include Associate Degree recipients).

The inclusion of educational attainment as part of polling criteria originated in the 1940's at the U.S. Census, with questions related to having a high school diploma and progressing to an undergraduate degree (in 2009) and finally evolving to educational attainment as the highest level of education that an individual has completed, which is distinct from the level of schooling that an individual is attending (U.S. Census Bureau, 2020b,c). Throughout 2020, the discussion of education level and political polling appeared to have gone mainstream, with a strong interest among writers, podcasters, journalists, and others who have written about the "College-Educated Voter."

While Hillary Clinton did not do well overall gaining White voters during the 2016 election, she did outperform Donald Trump with one subgroup: White, College-Educated women. Clinton lost the non-college education category of White men nationally (by 31 points) and non-College-Educated women (by 27 points) (Bitecofer, 2018). Bitecofer was more accurate than most other poll analysts in her forecasting model and use of predictors for the 2018 Democratic Party Vote including College-Educated, White, Latino, and the Partisan Voting Index $^{1}$ (Bitecofer, 2019).

A poll could be described as nationally representative and still not have solid methodology (Skelley \& Rakich, 2020). Two critics of poor polling in 2016 were Nate Cohn of

\footnotetext{
${ }^{1}$ (Partisan Voting Index or PVI as originally identified by Cook as a measure of how strongly a congressional district leans toward a specific party, from Wasserman \& Flinn, 2017)
} 
the New York Times and Nate Silver of FiveThirtyEight, who wrote that the education levels of polling participants were not weighted properly to reflect education levels in the states (as evidenced by the surge Clinton had in the 50 most educated counties) (Cohn, 2017a,b; Silver, 2016). Yglesias (2019) studied polling in Georgia and found when participants were not weighted properly to reflect that Georgia had a larger proportion of Whites who did not attend college compared to other states, the results tended to skew more in the direction of the Democratic party.

Since 2016, changes have been implemented to address low response rates and better polling. According to Jeff Howitt, who polls for NBC News/Wall Street Journal (on behalf of Hart Research), many polls have been weighted more by education level than before. As with many pollsters during the 2016 election, Horwitt indicated that they might be underestimating those without a four-year degree, which would underrepresent voters with little or no college education and a significant number of Trump supporters (Clement \& Guskin, 2020; Hart Research Associates, 2020).

Clarification of terms surrounding the educational background of voters could support understanding the preferences of voters who claim to be "Independent" or "Undecided." These blocks of voters are becoming more and more important in not just forecasting elections but in election outcomes. In 2020, according to national polls, there were about five percent of voters still undecided with two weeks to go until the election. Thad Kousser, of the UC San Diego Political Science Department, indicated that six to seven percent of those voters were in key battleground states during the last week in October of 2020, and they tend to vote with a hunch, while independent voters tend to lean toward a certain party (CBS San Diego, 2020). Undecideds are hard to pin down and could choose not to vote, or their vote may be critical when 
it comes to close races (Forgey, 2020; Pew Research Center, 2019; Stewart, 2020; Wronski, 2020).

The Independent's role in voting appears to not just depend on which direction they lean, but whether they vote at all and what issues are driving them. Almost three-fourths of those who identify as Independent appear to be partisan (as illustrated when polled on their issue preferences), however, they do not vote as often as those who identify as Republican and Democrat (Pew Research Center, 2019). In a survey of Independents taken recently by CNBC and others, Independents have lower approval ratings for Trump than Republicans, but are higher than Democrats. According to a New York Times survey in May, 2020, 11 percent of Democrats approved of the job Trump was doing as President, 91 percent of Republicans approved, and 41 percent of Independents approved (Wronski, 2020). The number of Independents is not only growing (with 36 percent of the electorate in this past election), but a larger number of Independents voted for Democrat Biden, in this election (54 percent), than Republican President Trump (41 percent) (The Fulcrum, 2020).

According to a survey of registered voters in 2018-19, when it comes to education, Independents were more likely than either Republicans or Democrats to have a four-year college degree or some college or less, Democrats were more likely to have postgraduate experience. Independents averaged the same as Democrats regarding percentages of voters with high school or less, while Republicans were more likely than both Independents and Democrats to be in the category of high school or less (Pew Research Center, 2020).

\section{Issues in Data Collection and Defining Categories}

To assist in better understanding voter behavior, the data collected by various polling entities should be consistent in definition of various polling criteria. It is best to begin with the 
largest and most consistent collection of data on voting preferences, the Current Population Voting and Registration Supplements. The U.S. Census Current Population Survey Voting and Registration Supplement collects information on the public's voting and registration preferences every two years (U.S. Census, 2020b).

In 2020, the Pew Research Center provided guidance to pollsters at the state level regarding how to best use the Current Population Survey Voting and Registration Supplements in a report titled "A Resource for State Pre-election Polling." In Table 1, voters are categorized as "High School or Less" "Some College" or "College Graduate" by collapsing several of the categories as recommended by Pew Research Center (Hatley \& Kennedy, 2020).

\begin{tabular}{|ll|}
\hline Table 1: Recommended Collapsed Education Categories \\
Detailed education category from CPS & Collapsed education category \\
None, preschool, or kindergarten & High school or less \\
Grades $1,2,3$, or 4 & High school or less \\
Grades 5 or 6 & High school or less \\
Grades 7 or 8 & High school or less \\
Grade 9 & High school or less \\
Grade 10 & High school or less \\
Grade 11 & High school or less \\
12 th grade, no diploma & High school or less \\
High school diploma or equivalent & High school or less \\
Some college but no degree & Some college \\
Associate degree, occupational/vocational program & Some college \\
Associate degree, academic program & Some college \\
Bachelor's degree & College graduate or higher \\
Master's degree & College graduate or higher \\
Professional School degree & College graduate or higher \\
Doctorate degree & College graduate or higher \\
\hline
\end{tabular}

Source: Hatley \& Kennedy, 2020.

Pollsters conducting political surveys often ask participants about their education level using categories similar to those listed in Table 1, but not always using the exact same terms as listed in the Census Population Survey Voting and Registration Supplement or the collapsed education categories as developed by the PEW Research Center. One example was NBC News 
polling as reported in July of 2020, on a widening lead for Democratic candidate Vice President Biden over President Trump. The online article on the poll provided a link to the questionnaire used in the poll by Hart Research Associates/Public Opinion Strategies/Vision Strategy and Insights which asked poll participants "What is The Last Grade That You Completed in School?" (Hart Research Associates, 2020).

Included in the questionnaire were instructions for those conducting the poll which indicated that participants were not to provide the education categories to respondents when asking this question. This means survey participants were self-identifying their education level. Participants were volunteering their own description of their education level and as a result those working the polls were left to decide how to categorize the participant using the categories in Table 2 (Hart Research Associates, 2020).

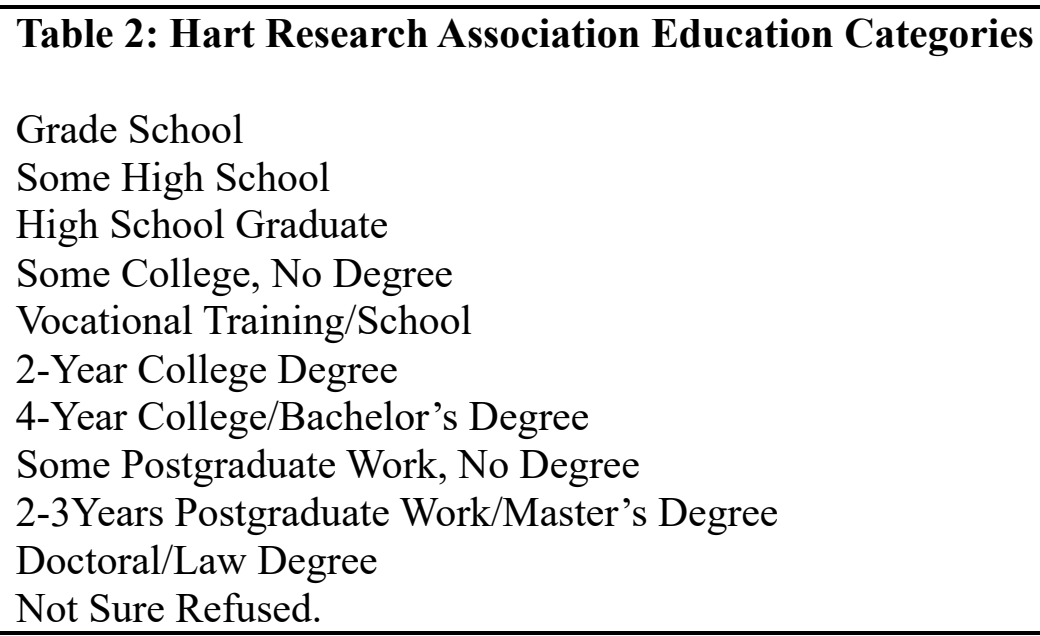

Source: Hart Research Associates, (2020). NBC News/Wall Street Journal Survey.

The Suffolk University/USA Today Poll used the following categories in Table 3, to describe education levels for participants in a poll of North Carolina voters who were surveyed in the fall of 2020 (Suffolk University, 2020). 


\section{Table 3: Suffolk University/USA Today National Poll Education Categories}

What is the highest level of education you have completed?

1. Some high school

2. High school graduate

3. Some college

4. Trade/technical/vocational training

5. College graduate

6. Masters or $\mathrm{PhD}$

7. Undecided

Source: Suffolk University, USA Today National Poll (2020).

While the description of the poll did not discuss education level in reporting on findings, it did provide a link to the questionnaire which provides evidence of a lack of clear categorization and definition regarding participant education level. It was not clear whether education level categories were provided to participants or whether participants self-identified their education levels. As Yglesias (2019) points out, when you don't weigh the results by education level, you can over and underestimate who is leading (such as underestimating Trump in 2016). The impact of education on not just political preference, but voting itself is significant (Harris, 2018).

\section{Data Analysis and Reporting}

Pasek and DeBell (2014) describe analyzing data from surveys as problematic especially in the areas of consistency and transparency. Consideration regarding weighting methods (as they used in the ANES survey data) can provide more clarity in the process. There are many challenges to analyzing data and reporting on polling of voter preferences in the context of the educational background of polling participants. Even simply describing the educational background of polling participants in a way that can be easily understood and provide a concise description as background for a larger article on polling can be a problem. Journalists 
interpreting survey data will sometimes use terms such as "those with a college education", "college graduates", "non-college graduates", "high education" and "low education" (Nietzel, 2020; The Economist 2019). Such labels can make it unclear as to how those voters with some college, or voters who graduated with Associate degrees, are being taken into account.

The numbers of Americans who have started college and not finished with any degree, or ended their college careers with an associate degree, are significant. According to Educational Attainment in the United States 2019 by the U.S. Census Bureau, of approximately 250 million Americans aged 18 and over, nearly ten percent ( 25 million) have associate degrees, and about 18 percent (45 million), attended college but have no degree (U.S. Census Bureau, 2020c). These two groups constitute around 28 percent (70 million) of those surveyed, close to the 33 percent ( 83 million) that have a bachelor or higher degree. When the terms "four-year college graduate" and "no college" are used in articles about college-educated voters, these groups literally represent approximately 33 percent and 39 percent of Americans, 18 years and above, respectively.

In using only those two terms, those analyzing college-educated voters are not clearly categorizing the roughly 28 percent of Americans above the age of 18 who received associate degree or some college but did not receive a degree. In which category are these people included in sampling and in the development of polling models? It seems that by the common use of "college graduate" or "four-year college graduate" in articles on college-educated voters, those who did not finish college or those with associate degrees are usually included with the 39 percent who only earned a high school diploma. But this often is not made clear in articles providing data and analysis of voter preferences. 
Given the recent interest and attention to College-Educated voters having, to use the terms recommended by the U.S. Census Bureau and Pew Research Center, "some college" or being "college graduates" it is important to look at how voters whose political preferences have been analyzed using these categories may lean in their choosing to vote for Democrats or Republicans (U.S. Census Bureau, 2020b; Pew Research Center, 2020). There can be differences regarding political party preference even within the category of "some college" depending on inclusion or exclusion of survey participants who have completed associate degrees. An example of this is the widely cited exit polling data collected and made easily available by $\mathrm{CNN}$.

In 2016 exit polling conducted by $\mathrm{CNN}$, there was no separation of participants who may have completed Associate Degrees or not (CNN Exit Polls, 2016). In 2018, the exit polling did separate out those participants. Those participants identified as having "some college" tended to vote for Democrats, and participants who had completed Associate Degrees leaned Republican (CNN Exit Polls, 2018). This means that if a survey is including Associate Degree recipients in their category of "some college" that additional data could be causing the entire category to skew Republican.

This issue of whether the categories are provided or whether survey participants are provided categories or definitions of their education level can be relevant as to how participants who earned Associate Degrees are analyzed. For example, Pew Research Center recommends including Associate Degree recipients as "Some College" (Pew Research Center, 2020). But it is possible that an individual who worked for years to earn an Associate Degree may be reluctant to self-identify as having "Some College" and may instead self-identify as "College Graduate". As the CNN data showing Associate Degree recipients in 2018 exit polls skewed Republican, there 
is the possibility that including Associate degree recipients in the category of "College Graduate" may cause that category to skew Republican.

Another reason that education levels matter in analysis of political polling data is that it further explains gender differences in voting. Polling has historically provided evidence that not only do women often vote differently than men, but College-Educated women tend to vote for Democrats and education is often associated with a higher turnout in the polls (Chinni, 2017; Pew Research Center, 2020). Most recently journalists analyzing voter behavior have focused on "College-Educated Women" in articles about women voters, but the data cited has been the result of polling that included women and men (Hartig, 2019; Tyson, 2018). According to Wolbrecht and Corder (2020), women today are more likely to have completed four years of college than men, which is due to major gains in their educational attainment since the 1940s. The Economist (2019) described what began in the 1970 as a partisan gap between College-Educated voters and less-educated voters due to the recruitment by the Republican Party of the latter group. The partisan gap in education was similar for both men and women until 1983, when women began to narrow the gap (in favor of the Democratic Party).

\section{The Research Questions}

What do we know about levels of college educational attainment and voting preferences? What data are available on the voting preferences of individuals who attended college and did not graduate with a four-year degree? In addition to the review of recent articles and reports provided earlier in this paper, a focused analysis of these issues was done using publicly available data from the U.S. House District level (U.S. Census, 2020a). This examination compares the link of college education and party preference in voting by using publicly available 
data on educational attainment of pools of eligible voters in geographical areas that clearly voted for one party or another.

\section{Analysis of Education Data and Vote in U.S. House Districts}

The U.S. Census Bureau provides data on U.S. House Districts that categorizes the education levels of adults 25 years old and above in detail, allowing for study of education level in districts that have had a history of being competitive, or districts that have a history of voting for Republican House members or voting for Democrats for the U.S. House (U.S. Census, 2020a). It is possible to compare education data from 2019 to look at the 2020 elections in competitive districts that went Republican, historically Republican districts and historically Democratic districts with similar population size of 25 -year-olds and above to see if proportions of college educated possible voters can make a difference in trying to model the educational composition of a U.S. House district.

In examining the educational profile of four predominantly Democratic Districts compared to four predominantly Republican districts, controlling for the number of adults 25 and over in the district, it is possible to see clear differences regarding populations of four-year college graduates and above compared to populations of those with high school diplomas and less education. The first set of data (Table 4) provides an educational profile of individuals who are 25 years old and above in four Congressional districts that voted heavily Democratic in 2020 and the second set of data is that same type of educational data for four Congressional districts that voted heavily Republican in 2020 (U.S. Census, 2020a). 


\begin{tabular}{|lrrrr|}
\hline \multicolumn{4}{|l}{ Table 4: Examination of Educational profiles of Democratic and Republican House Districts } \\
State and House District Number & NY 19 & MA 2 & HI 1 & CA 11 \\
Percentage vote 2020 Dem - Rep & $54.5-42.9$ & $65.3-34.6$ & $72-28$ & $73-27$ \\
Population 25 years and over & 508,208 & 520,484 & 516,378 & 535,458 \\
Percent bachelor's degree or higher & $31.20 \%$ & $40.71 \%$ & $36.71 \%$ & $44.78 \%$ \\
Some Coll. And Assoc. Deg. \% of pop 25+ & $28.45 \%$ & $25.82 \%$ & $30.60 \%$ & $26.35 \%$ \\
High School Grad or less as a \% of pop 25+ & $40.35 \%$ & $33.46 \%$ & $32.68 \%$ & $28.88 \%$ \\
& & & & \\
State and House District Number & MI 1 & KY 2 & WI 7 & TN 7 \\
Percentage vote 2020 Rep - Dem & $61.6-36.8$ & $71-26.3$ & $60.8-39.2$ & $69.9-27.3$ \\
Population 25 years and over & 512,016 & 520,460 & 515,418 & 532,755 \\
Percent bachelor's degree or higher & $26.17 \%$ & $21.92 \%$ & $24.41 \%$ & $32.11 \%$ \\
Some Coll. And Assoc. Deg. \% of pop 25+ & $33.94 \%$ & $30.72 \%$ & $33.56 \%$ & $26.28 \%$ \\
High School Grad or less \% of pop 25+ & $39.90 \%$ & $47.37 \%$ & $42.03 \%$ & $41.61 \%$ \\
\hline
\end{tabular}

Source(s): US Census (2020a); National Election Pool (2020). ${ }^{2}$

The data in Table 4 reflects the national polling information regarding education and party affiliation. There is a clear pattern of Democratic districts having larger percentages of adults 25 and older with college degrees or higher, and the Republican districts having a larger percentage of adults 25 and older categorized as High School graduates or having less education. Competitive districts that went Republican with predominantly Republican and predominantly Democratic districts were compared in Table 5.

${ }^{2}$ Percentages were calculated using data provided from the U.S. Census tables. There may be slight differences between percentages of bachelor's degree or higher in this table compared with the data on the Web site due to rounding. 


\begin{tabular}{|c|c|c|c|c|}
\hline State and House District Number & IN 5 & NJ 2 & IA 2 & VA 5 \\
\hline Percentage 2020 Competitive Rep - Dem & $50-45.9$ & $51.9-46.2$ & $50-50$ & $52.6-47.4$ \\
\hline Population 25 years and over & 537,171 & 503,363 & 528,357 & 522,039 \\
\hline Percent bachelor's degree or higher & $47.86 \%$ & $27.18 \%$ & $28.36 \%$ & $29.02 \%$ \\
\hline Some Coll. And Assoc. Deg.\% of pop 25+ & $24.37 \%$ & $26.06 \%$ & $31.87 \%$ & $29.19 \%$ \\
\hline High School Grad or less \% of pop $25+$ & $27.77 \%$ & $46.76 \%$ & $39.78 \%$ & $41.80 \%$ \\
\hline State and House District Number & OK 1 & IA 4 & SC 7 & TN 1 \\
\hline Percentage vote 2020, 4 Republican Districts & $63.7-32.7$ & $62.1-37.9$ & $61.8-38.2$ & $74.7-22.5$ \\
\hline Population 25 years and over & 538,008 & 502,738 & 533,350 & 521,341 \\
\hline Percent bachelor's degree or higher & $32.03 \%$ & $25.42 \%$ & $22.41 \%$ & $21.90 \%$ \\
\hline Some Coll. And Assoc. Deg. \% of pop 25+ & $31.36 \%$ & $33.98 \%$ & $29.45 \%$ & $27.52 \%$ \\
\hline High School Grad or less \% of pop $25+$ & $36.61 \%$ & $40.60 \%$ & $48.14 \%$ & $50.58 \%$ \\
\hline State and House District Number & WA 2 & IN 7 & VA 4 & WI 2 \\
\hline Percentage vote 2020, 4 Democratic Districts & $63.1-36.7$ & $62.4-37.6$ & $61.7-38.3$ & $69.7-30.3$ \\
\hline Population 25 years and over & 536,360 & 503,912 & 533,621 & 521,266 \\
\hline Percent bachelor's degree or higher & $33.43 \%$ & $24.98 \%$ & $30.83 \%$ & $44.93 \%$ \\
\hline Some Coll. And Assoc. Deg. \% of pop 25+ & $36.97 \%$ & $26.74 \%$ & $28.95 \%$ & $26.98 \%$ \\
\hline High School Grad or less \% of pop $25+$ & $29.60 \%$ & $48.28 \%$ & $40.22 \%$ & $28.10 \%$ \\
\hline
\end{tabular}

Source(s): US Census (2020a); The National Election Pool (2020). ${ }^{3}$

Examination of the data in this Table 5 was limited to districts with similar population sizes for the total amount of individuals in the district who were 25 and older. The competitive districts were representative of the Republican districts in the higher percentages of people who had earned a High School diploma or had less education compared with the percentages of people who had earned a bachelor's degree or higher.

${ }^{3}$ Percentages were calculated using data provided from the U.S. Census tables. There may be slight differences between percentages of bachelor's degree or higher in this table compared with the data on the Web site due to rounding. 
In Tables 4 and 5, the proportion of individuals with some college and an associate degree reveals no clear pattern. In Table 4 , those percentages range from $25.82 \%$ to as high as $33.94 \%$. In Table 5, those percentages range from a low of $26.74 \%$ to a high of $36.97 \%$ (U.S. Census, 2020a). These individuals constitute a quarter to a third of the possible voters in each of these districts, a significant proportion that is worthy of closer study.

\section{Conclusion}

As the general public shows more concern over how polling predicted the 2020 election results, and in the wake of the 2016 election, more attention is being paid to polling than ever before (Pew Research Center, 2020). Clearly explaining the meaning of various terms surrounding education and voting preferences is important because reporting of polling data has received more and more attention beyond political scientists and pundits. Mainstream media outlets are presenting and interpreting complex political polling data in articles about the quality of political polling. These reflect some skepticism and concern about the details surrounding the polling, for example logistics (by phone or on-line), sample sizes, response rates, focus on the educational background of those polled and who is being polled. Therefore, it is important how survey participants identify their education level, with categories of some college or an Associate Degree being collapsed into categories of college graduates and non-college graduates.

While most articles on political polling do not include definitions of these terms, often on-line articles do provide links to surveys and/or cross tabs of survey questions and/or procedures, that include more detail. But often that data does not get more detailed than two categories that delineate voters into "College-Educated" and "Non-College-Educated", with either no clear definition of these terms or various pollsters defining these terms differently. 
One of the key elements identified as having a significant impact on polling is education level. For the sake of the field, some type of consistency in defining what a college-educated voter represents, is necessary to provide a true picture of the effect of education level on voter preferences. Additionally, it would be helpful if those reporting on polling results were clearer and more concise in their analysis and reporting of political polling data, especially when using the term College-Educated voter. As Kennedy (2020) notes, narrowing the gap between perception and reality when it comes to polling will help reduce the skepticism about surveys. This can be done through more accurate analysis and consistency in definitions, leading to improved interpretation by the media. 


\section{References}

American Association for Public Opinion Research (AAPOR) (2017). An Evaluation of the 2016 Election Polls in the U.S. Retrieved from: https://www.aapor.org/EducationResources/Reports/An-Evaluation-of-2016-Election-Polls-in-the-U-S.aspx

Arnold, L. (2020). “The Gender Gap in Voting.” The Atlantic.

Bitecofer, R. (2018). The Unprecedented 2016 Presidential Election. Palgrave Macmillan: London.

Bitecofer, R. (July 1, 2019). With 16 months to go, negative partisanship predicts the 2020 Presidential Election. The Wasson Center, https://cnu.edu/wasoncenter/2019/07/01-2020election-forecast/

CBS San Diego (2020). "How many undecided voters are left?" [Video file]. YouTube, (October 22, 2020). https://youtu.be/MHVOqv8Uds4.

Chinni, D. (December 27, 2017). More Educated Women Favor Democrats College Educated Women Favor Democrats. Wall Street Journal.

Clement, S. \& Guskin, E. (October 16, 2020). How the Washington Post's polling average works. The Washington Post. https://www.washingtonpost.com/politics/2020/10/16/washington-post-polling-average/

CNBC. “Are polls trustworthy?" [Video]. YouTube, (October 26, 2020). https://youtu.be/UxpHI53T3zs

CNN, (November 23, 2016). Exit polls. https://www.cnn.com/election/2016/results/exit-polls, CNN, (November 5, 2018). Exit polls. https://www.cnn.com/election/2018/exit-polls, 
Cohn, N. (2017a). A 2016 Review: Why key state polls were wrong about Trump. New York Times. https://www.nytimes.com/2017/05/31/upshot/a-2016-review-why-key-state-pollswere-wrong-about-trump.html

Cohn, N. (2017b). After a tough 2016, many pollsters haven't changed anything. New York Times, https://www.nytimes.com/2017/11/06/upshot/after-a-tough-2016-many-pollstershavent-changed-anything.html

Dimock, M. (2020). What we can trust 2020 election polls to tell us. Pew Research Center. https://www.Pewresearch.org/fact-tank/2020/10/29/what-we-can-trust-2020-electionpolls-to-tell-us/

Forgey, Q. (Sept. 17, 2020). North Carolina poll shows close races for White House, Senate. Politico. https://www.politico.com/news/2020/09/17/north-carolina-elections-poll416965

Harris, A. “America Is Divided by Education.” The Atlantic, (November 7, 2018). https://www.theatlantic.com/education/archive/2018/11/education-gap-explains-americanpolitics/575113/?utm_source=share\&utm_campaign=share

Hart Research Associates, (2020). NBC News/Wall Street Journal Survey. The Wall Street Journal.

Hartig, H. (2019). Gender gap widens in views of government's role and of Trump. Pew Research Center. Retrieved from: https:/www.Pewresearch.org/fact$\underline{\text { tank/2019/04/11/gender-gap-widens-in-views-of-governments-role-and-of-trump/ }}$

Hatley, N., \& Kennedy, C. (2020). A Resource for State Preelection Polling. Pew Research Center. https://www.Pewresearch.org/methods/wpcontent/uploads/sites/10/2020/08/PM_08.18.20_state.polling.education.FINAL_.pdf 
Igielnik, R., Keeter, S., \& Hartig, H. (2021). Behind Biden’s 2020 Victory: An examination of the 2020 electorate, based on validated voters. PEW Research Center.

Kennedy, C. (2020). Key things to know about election polling in the United States. Pew Research Center. Retrieved from: https://www.Pewresearch.org/fact-tank/2020/08/05/keythings-to-know-about-election-polling-in-the-united-states/

Leonhardt, D. (2020). A Black Eye: Why political polling missed the mark. Again. The New York Times.

Mercer, A. (2016). 5 Key things to know about the margin of error in election polls. PEW Research Center, Retrieved from: https://www.Pewresearch.org/facttank/2016/09/08/understanding-the-margin-of-error-in-election-polls/

National Election Pool (2020). U.S. House Election Results 2020 NBC News Decision Desk. Reported by NBC News Decision Desk. Retrieved from: nbcnews.com/politics/2020elections/house-results

Nietzel, M. (June 15, 2020). Biden vs. Trump: the college education divide is wider than ever. Forbes.

Pasek, J. \& DeBell, M. (2014). Standardizing and Democratizing Survey Weights: The ANEW Weighting System and Anesrake. Retrieved from: https://docs.google.com/viewer?url=https\%3A\%2F\%2Fsurveyinsights.org\%2Fwpcontent $\% 2$ Fuploads $\% 2$ F2014\%2F07\%2FFull-anesrake-paper.pdf

Pew Research Center (2020). In Changing U.S. Electorate, Race and Education Remain Stark Dividing Lines. Pew Research Center. Retrieved from: https://www.Pewresearch.org/politics/2020/06/02/in-changing-u-s-electorate-race-andeducation-remain-stark-dividing-lines/ 
Pew Research Center (2019). Political Independents: Who they are and what they think. Pew Research Center. Retrieved from:

https://www.Pewresearch.org/politics/2019/03/14/political-independents-who-they-arewhat-they-think/

Silver, N. (2016, November 22). Education, not income, predicted who would vote for Trump. FiveThirtyEight.

Skelley, G. \& Rakich, N. (2020). What pollsters have changed since 2016 - and what still worries them about 2020. FiveThirtyEight. Retrieved: https://fivethirtyeight.com/features/whatpollsters-have-changed-since-2016-and-what-still-worries-them-about-2020/

Stewart, E. (2020). Undecided voters explain themselves.”Vox.

Suffolk University (2020). USA Today National Polls. Retrieved from: https://www.suffolk.edu/academics/research-at-suffolk/political-researchcenter/polls/national $/ 2020$

The Economist (2019). Poorly educated voters hold the key to the white house. The Economist, Retrieved: https:/www.proquest.com/magazines/poorly-educated-voters-hold-keyswhite-house/docview/2313768119/se-2?accountid=7113

The Fulcrum, (2020). Independents vital to Biden win, boon to a good-governance cause. The Fulcrum.

Tyson, A., (2018). The 2018 midterm vote: Divisions by race, gender, education. Pew Research Center. Retrieved from: https://www.Pewresearch.org/fact-tank/2018/11/08/the-2018midterm-vote-divisions-by-race-gender-education/

U.S. Census Bureau (2020a). My Congressional District. Retrieved from https://www.census.gov/mycd/ 
U.S. Census Bureau, (2020b). Why we ask each question. U.S. Census.

U.S. Census Bureau, (2020c). Educational Attainment in the United States: 2019. U.S. Census.

Wasserman, D. and Flinn, A. (2017). Introducing the 2017 Cook Political Report Partisan Voter Index. Cook Political Report.

Wolbrecht, C. \& Corder, J. K. (2020). A Century of Votes for Women: American Elections Since Suffrage. Cambridge University Press: United Kingdom.

Wronski, L. “New York Times/SurveyMonkey poll: May 2020.” Survey Monkey. (2020). https://www.surveymonkey.com/curiosity/nyt-may-2020-cci/.

Yglesias, M. (2019). The Difference Between Good and Bad State Polls, Explained. Vox. 